\title{
回归建筑本源的建筑设计实践 一一幼儿园课程模块化搭建
}

\author{
Architectural Design Practice Returning to Architectural Origin \\ -Modular Construction of Kindergarten Courses \\ 杜婷
}

Ting Du

滨州学院

中国·山东 滨州 256600

Binzhou University,

Binzhou, Shandong, 256600, China

\section{1 基本问题}

什么是建筑设计的基本问题, 不同角度和层面有不同的 解读和侧重, 从适用、安全、经济、美观到形式、空间、文脉、绿 色等, 都是在探讨建筑的本质内涵与建筑设计需要解决的基 本问题 ${ }^{[1]}$ 。

建筑创作是一个综合性很强、似乎不能完全理性控制的 过程。幼儿园课程设计是本科生在完成建筑设计基础学习阶 段后, 进入的第一个完整建筑的设计课程。在这个课程之前, 有一个以学生自我经验为依据, 进行单一建筑空间搭建与组 织的设计联系, 幼儿园课程设计在此基础上展开、深人, 训练 学生对重复空间的组织能力。

幼儿园设计需要针对特殊的服务对象一幼儿。课程设 计训练学生对特殊使用者尺度、行为以及建筑方式的调研认
知,设计符合特殊使用者的建筑与空间。在刚开始进入专业学 习的过程中, 强化使用人群这个建筑最本质要素在建筑设计 中的主导作用。

另一方面, 建筑空间的组织与营建, 虽然综合性强、复杂度 高, 也是可以分化和拆解的, 在幼儿园课程设计教学中, 有针 对性的设置不同模块, 从易到难、从点到面, 让学生明确概念, 掌握空间设计与场景营建的基本方法 ${ }^{[2]}$ 。

\section{2 课程模块搭建}

幼儿园课程设计以使用者认知、情景想象、空间组织、表 皮建构、场景呈现 5 个模块为主线。

\section{1 幼儿尺度与行为认知模块}

作为一个设计师, 没有使用感受很难做出好的设计, 不是 每个类型的建筑都能让设计师有切身体验, 无法体验的建筑 类型该如何设计, 是每个设计师职业生涯都将会遇到的问题。 
幼儿园课程设计就是这样的建筑类型。人们都经历过幼 儿时代, 可惜太过遥远, 几乎无法回忆, 这就要求学生重新认 识幼儿, 能从幼儿的角度看待一个建筑, 并且还必须符合幼儿 以及成年人的使用需求。也只有这种题目的设置, 才会使学生 深刻明白服务对象在建筑中所起到的作用。

因此课程设置了 2 个环节: 幼儿尺度实验;幼儿行为活动 调研。

\section{1 .1 幼儿尺度实验}

尺度是一个看似具象, 实际非常抽象的问题。尺度永远都 不是绝对的,而是相对的。

尺度是空间的决定要素, 是人们教学实践的难点和重点。 尺度如何理解和呈现, 对成熟建筑师都是一个难题, 更何况是 初学设计的学生。所以必须由老师来引导, 先以老师观察和理 解的视角, 取呈现尺度概念, 再指引学生通过分析和解析去认 识和理解尺度与建筑空间、建筑构件的关系。

以尺度读本为基础,学生需要深入理解和分析空间中的 尺度关系, 通过图示的成果, 表达自己对幼儿尺度、空间尺 度、构件尺度相互关联的分析和认知, 并最终指导课程设计 的进行 ${ }^{[3]}$ 。

\subsection{2 幼儿行为调研认知}

行为活动调研需要学生跟拍一个或多个幼儿全天的活 动, 收集剪裁网络相关幼儿活动的视频, 综合以一个短视频的 方式展示自己对幼儿活动特点的分析和理解。

这 2 个感性认知的练习, 会指导学生在生成幼儿园课程 设计主题的探讨中最终呈现不同的抽象场景，为整个设计奠 定不同的色彩基调。

\section{2 情景想象模块}

经过尺度与行为的认知, 引导学生对童年生活的回忆以 及对身边幼儿行为活动特征的观察, 激发学生的观察力、感知 力以及想象力, 并以图示语言将空间场景进行抽象表达。这个 阶段训练的是学生对事件的描述, 是否可以抽象地提炼出对 场景的表达, 以及建筑空间的塑造。

\section{3 游戏盒子一一空间组织模块}

通过前 2 个模块的训练, 将抽象的概念元素转化为形式 化的建筑设计, 从而明确设计的起点。通过对幼儿行为尺度认 识的应用,在开始设计之前, 学生需要根据要求设计一个小尺 度的儿童交往空间——“游戏盒子”。

“游戏盒子”需要体现以下空间特质: 以幼儿尺度与行为 活动特点为依据, 设计空间、尺度及游戏方式。界面可以是开 放的,可根据自己的设计确定进人方式。

\section{4 表皮建构模块}

在以往的教学中, 尤其是在低年级教学中, 建筑设计课程 与其他理论课程, 比如, 建筑构造、建筑材料、建筑结构等完全 分离。建筑设计课程中需要解决的相关问题,学生也无法理解 本质, 仅仅在做纯形式的立面和表皮。如何实现这些课程的融 会贯通是需要思考和解决的难点。

在设计课程中并没有回避这个问题，尝试结合学生同期 开始的建筑构造和建筑结构课程, 设计课程模块, 将理论转化 成实际的建筑设计。当然, 构造对低年级学生, 不是容易的事 情, 幼儿园课程设计主要针对墙身、墙面窗户节点和墙身接地 节点 3 个部位进行认知和设计, 使学生明确认识到建筑立面、 形体设计与建筑围护的密切关系。

\section{5 场景呈现模块}

通过前几个课程模块的一系列设计训练, 从而让学生可以 转换思维视角, 能够从幼儿的角度去看待建筑空间, 并且适应 幼儿行为认知下的空间营造策略。从概念意向的空间设计中, 抽取提炼空间秩序; 从“游戏盒子”的空间装置设计中, 明确尺 度的应用; 从单元空间的多样性设计中, 探讨空间的精细化; 从重复空间的组合模式中, 对空间进行整合, 进而完成整个设 计。形成整体空间场景的营造, 设计出适合幼儿尺度与行为模 式的建筑空间与场所空间。

\section{3 结语}

作为建筑专业最重要的职业训练一课程设计，必须以 本源问题为导向, 贯穿始终, 由易到难, 循序渐进地指引学生 接近建筑的本质,适应社会的发展与需求。

合格的设计师是生活的有心人,体验未知、观察周边和学 习技术, 才能越来越接近建筑的本质, 创造有社会意义和价值 的存在。

在幼儿园课程设计的教学实践中, 人们会继续探讨如何 将尺度的认知和理解在设计中实现，体现尺度变化所带来的 建筑空间形式的变化。同时,研究建立在设计课和技术理论课 共同基础上的作业评价体系的可能性，制定作业及考核成果 在课程之间的共享原则, 使模块化课程的融合和互相促进更 加充分, 提高学生的有效学习, 激发学生对建筑根本问题更深 入的思考和探索。

\section{参考文献}

[1]吴良镰.广义建筑学[M].北京:清华大学出版社,1989.

[2]邓庆坦. 托儿所幼儿园建筑设计图说[M]. 济南: 山东科学技术 出版社,2006.

[3]蔡春美.幼儿行为观察与记录[M].上海:华东师范大学出版社, 2013. 